\title{
Glucagon-like peptide 2 therapy reduces negative effects of diarrhea on calf gut
}

\author{
E. E. Connor, ${ }^{* 1}$ S. Kahl, ${ }^{*}$ T. H. Elsasser, ${ }^{*}$ R. L. Baldwin VI, ${ }^{*}$ R. Fayer, $†$ M. Santin-Duran, $\dagger$ \\ G. L. Sample $\ddagger$ and C. M. Evock-Clover* \\ *Bovine Functional Genomics Laboratory, \\ †Environmental Microbial and Food Safety Laboratory, and \\ ¥Veterinary Services, USDA, Agricultural Research Service, Beltsville, MD 20705
}

\begin{abstract}
Damage to the intestinal epithelium reduces nutrient absorption and animal growth, and can have negative long-term health effects on livestock. Because the intestinotropic hormone glucagon-like peptide 2 (GLP-2) has been shown to contribute to gut integrity, reduce inflammation, and improve nutrient absorption, the present study was designed to determine whether administration of GLP-2 to calves with coccidiosis in the first month of life affects intestinal growth and mediates negative effects of the proinflammatory response. Holstein bull calves $(\mathrm{n}=19)$ were assigned to 4 treatment groups of 4 to 5 calves each: (1) infected with Eimeria bovis, GLP-2 treated; (2) noninfected, GLP-2 treated; (3) infected with E. bovis, buffer treated; and (4) noninfected, buffer treated. Infected calves received 100,000 to 200,000 sporulated E. bovis oocysts suspended in milk replacer on d 0 of the study. On d 18, calves in the GLP-2 groups received a subcutaneous injection of 50 $\mu \mathrm{g}$ of bovine GLP-2 $/ \mathrm{kg}$ of body weight twice daily for $10 \mathrm{~d}$, and calves in the buffer-treated groups received an equivalent volume of sodium bicarbonate buffer only. On d 28, calves were slaughtered $2 \mathrm{~h}$ after injection of 5-bromo-2'-deoxyuridine (BrdU). Intestinal tissues were measured and villus height, crypt depth, and BrdU immunostaining were evaluated in segments of the small intestine. Nitrotyrosine immunostaining, a measure of nitro-oxidative damage, was evaluated in the ileum and cecum. No GLP-2 treatment by E. bovis infection interaction was observed for any parameter measured, with the exception of nitrotyrosine immunostaining in the cecum. Large intestinal weight was greater in infected than noninfected calves and with GLP-2 treatment relative to buffer treatment. Calves that received GLP-2 also had greater small intestinal weight but no difference in cell proliferation, as assessed by BrdU la-
\end{abstract}

Received October 1, 2012.

Accepted November 12, 2012.

${ }^{1}$ Corresponding author: erin.connor@ars.usda.gov beling, relative to buffer-treated calves. No treatment effects were detected for villus height, crypt depth, or villus height:crypt depth ratio in segments of the small intestine. Protein tyrosine nitration was over 3 -fold greater in the ileum and cecum of infected calves relative to noninfected calves, and GLP-2 therapy reduced tyrosine nitration in infected calves by $47 \%$ in the ileum and $69 \%$ in the cecum relative to buffer-treated calves. Treatment with GLP-2 promotes intestinal growth in neonatal calves and reduces the detrimental effects of nitro-oxidative stress in the ileocecum of calves with coccidiosis.

Key words: calf diarrhea, coccidiosis, glucagon-like peptide 2, nitrotyrosine

\section{INTRODUCTION}

In the young dairy calf, poor health in early life can have long-term negative effects on production. For instance, the number of days that a heifer calf has diarrhea during the first $4 \mathrm{mo}$ of life has a significant negative effect on 305-d mature equivalent milk production and actual milk, protein, and fat production in the first lactation (Heinrichs and Heinrichs, 2011). Thus, therapies that reduce the duration of calf diarrhea could increase subsequent milk production efficiency. In monogastric species, an intestinotropic peptide hormone produced by intestinal L cells called glucagon-like peptide 2 (GLP-2) has been administered therapeutically to modulate nutrient absorption in the small intestine (Drucker, 2005). In humans and rodents, GLP-2 treatment stimulated proliferation of intestinal crypt cells, reduced apoptosis of intestinal mucosal epithelium, improved intestinal integrity after injury, suppressed inflammation in the gut, and enhanced nutrient absorption (Lovshin and Drucker, 2000; Burrin et al., 2003a; Drucker, 2005). Based on these findings, the peptide could be a useful therapeutic for enhancing gut function and nutrient use in cattle with diarrhea (Burrin et al., 2003b) if its effects are similar between monogastric and ruminant species. 
Recently, it was determined that GLP-2 pathway members including its parent peptide, receptor, and 2 enzymes controlling its release and activity are expressed in the digestive tract of dairy cattle and that GLP-2 may serve functional roles in intestinal growth and development of ruminants (Connor et al., 2010). Furthermore, Taylor-Edwards et al. (2011) demonstrated increased epithelial mass of the ileum and jejunum, increased villus height and crypt depth in the duodenum and jejunum, and increased cell proliferation in all 3 segments of the small intestine of ruminating calves. Additionally, those authors showed that intravenous administration of GLP-2 elicits an increase in blood flow to the small intestine via the superior mesenteric artery. Therefore, the functions and effects of GLP-2 on the gastrointestinal tract of cattle appear to be similar to those observed in monogastric species, suggesting that study of its potential use as a therapy to improve intestinal function in calves with diarrhea warrants further investigation.

The objective of the present study was to determine whether the negative effects of intestinal infection caused by coccidiosis in dairy calves can be alleviated by GLP-2 therapy. Our hypothesis was that GLP-2 treatment would increase cell proliferation, villus height, and crypt depth, and reduce nitro-oxidative damage in the ileocecum of calves experimentally infected with Eimeria bovis compared with infected, buffer-treated calves.

\section{MATERIALS AND METHODS}

All procedures involving animals were approved by the Beltsville Area Animal Care and Use Committee protocol number 10-023.

\section{Animals}

Holstein bull calves $(\mathrm{n}=19)$ were purchased from a local private dairy or were obtained from the Beltsville Agricultural Research Center (BARC) herd. Calves were fed colostrum at their first feeding and transported as soon as possible after birth to an environmentally controlled building on the BARC research campus where they were housed in individual concrete pens $\left(7.3 \mathrm{~m}^{2}\right)$ bedded with straw. Calves received $5 \mathrm{~mL}$ of penicillin $\mathrm{G}$ benzathine and penicillin $\mathrm{G}$ procaine, $2.5 \mathrm{~mL}$ of BO-SE (Merck Animal Health, Summit, NJ), $3 \mathrm{~mL}$ of vitamin C, $1 \mathrm{~mL}$ of vitamins $\mathrm{A}$ and $\mathrm{D}, 2 \mathrm{~mL}$ of iron dextran, and $35 \mathrm{~mL}$ of Quatracon- $2 \times$ (Boehringer Ingelheim Vetmedica Inc., St. Joseph, MO) and were confirmed negative for bovine viral diarrhea by a PCRbased blood test conducted by the Cornell University Animal Health Diagnostic Center (Ithaca, NY). Fecal examination of all calves at arrival to the experimental barn also confirmed the absence of any parasites or eggs. All calves were provided continuous access to water and fed twice daily $(1.9 \mathrm{~L}$ per feeding for a total of $3.8 \mathrm{~L} / \mathrm{d}$ ) commercial milk replacer (Cornerstone 22:20; Purina Mills LLC, St. Louis, MO; $22.0 \%$ CP, $20.0 \%$ crude fat, $0.15 \%$ crude fiber, 0.75 to $1.25 \% \mathrm{Ca}, 0.70 \%$ $\mathrm{P}, 66,000 \mathrm{IU}$ of vitamin $\mathrm{A} / \mathrm{kg}, 11,000 \mathrm{IU}$ of vitamin $\mathrm{D}_{3} /$ $\mathrm{kg}$, and $220 \mathrm{IU}$ of vitamin $\mathrm{E} / \mathrm{kg}$ ). In addition, calves had ad libitum access to grain (Bel Air Calf Starter $22 \%$; Bel Air, MD; $22.0 \%$ CP, $4.0 \%$ crude fat, and $5.5 \%$ crude fiber) and orchard grass hay.

\section{Experimental Design}

The experimental design was a randomized block with 5 blocks and 4 treatment groups. The 4 treatment groups were (1) infected with E. bovis, GLP-2 treated (Eim-GLP2; n = 5); (2) noninfected, GLP-2 treated (Con-GLP2; $\mathrm{n}=4$ ); (3) infected with E. bovis, buffer treated (Eim-Buffer; n = 5); and (4) noninfected, buffer treated (Con-Buffer; n = 5). In block 3, the Con-GLP2 group was omitted due to an unexpected GLP-2 peptide synthesis failure during manufacturing, limiting the quantity available for administration. All calves were weighed by d 1 of age, paired by weight, and assigned to receive either GLP-2 or buffer, and then were randomly assigned to E. bovis-infected or noninfected groups. On d 0 of the study, mean $( \pm \mathrm{SD})$ calf age was $11( \pm 3) \mathrm{d}$ and BW was $43( \pm 4) \mathrm{kg}$.

\section{Eimeria bovis Infection}

On d 0 of the study, all calves were fed their normal morning ration of milk replacer using a nippled bottle. The bottle of milk replacer of each calf in the EimBuffer and Eim-GLP2 groups was spiked with 200,000 sporulated oocysts of Eimeria bovis [kindly provided by A. Lucas, Virginia Polytechnic Institute and State University (VPI and SU), Blacksburg, VA]. Note that 100,000 oocysts were used in block 1 but the number was increased in subsequent blocks to 200,000 to increase the diarrhea response, as the severity of diarrhea among infected calves in block 1 was not as great as desired. All calves also were weighed on d $-1,5,11,16$, 21 , and 26 of the study to monitor growth during the trial and to determine the appropriate doses of GLP-2 (or buffer) to administer throughout the study.

For the last $11 \mathrm{~d}$ of each experimental period, a fecal sample was collected for determination of the presence of oocysts, and fecal scores for each calf were recorded twice daily where $0=$ normal stool; $1=$ loose stool with some form; 2 = stool not formed, pudding-like; and 3 $=$ watery stool with no solids present. The number of 
days that feces were not normal (nonzero value) was totaled for each calf and the mean fecal score during those days was calculated.

\section{GLP-2 Administration}

Bovine GLP-2 (AA 1 to 34 of the native bovine sequence, 90 to $95 \%$ purity) was synthesized by California Peptide Research Inc. (Napa, CA) or AAPPTec LLC (Louisville, KY) and stored lyophilized at $-20^{\circ} \mathrm{C}$ until the day of injection. The peptide was dissolved in sterile-filtered $0.1 M$ sodium carbonate/bicarbonate (pH 8.5) to obtain a concentration of $10 \mathrm{mg} / \mathrm{mL}$ and then was diluted 10 fold with sterile-filtered deionized water to obtain a final concentration of $1.0 \mathrm{mg} / \mathrm{mL}$ in $0.01 M$ sodium carbonate/bicarbonate. For 10 consecutive days (d 18 to 27 of the study), Con-GLP2 and Eim-GLP2 calves were injected every $12 \mathrm{~h}$ with $50 \mu \mathrm{g}$ of GLP-2 $/ \mathrm{kg}$ of BW (i.e., $100 \mu \mathrm{g} / \mathrm{d}$ ). The Eim-Buffer and Con-Buffer calves were injected every $12 \mathrm{~h}$ with equivalent volumes of $0.01 \mathrm{M}$ sodium carbonate/bicarbonate ( $\mathrm{pH} 8.5)$.

\section{Tissue Collection}

On d 28, calves were administered a bolus intravenous injection of 5-bromo-2'-deoxyuridine (BrdU; Sigma-Aldrich, St. Louis, MO; $20 \mathrm{mg} / \mathrm{mL}$ in $0.9 \%$ sterile saline, $\mathrm{pH} 8.2 ; 5 \mathrm{mg} / \mathrm{kg}$ of $\mathrm{BW}$ ) through the jugular vein $2 \mathrm{~h}$ before slaughter to monitor cell proliferation in the small intestine. Calves were stunned by a penetrating captive bolt followed by exsanguination at the BARC abattoir. The complete digestive tract was removed, processed as described by McLeod et al. (2007), and the following measurements were recorded: wet weight of large intestines, including the rectum; wet weight of small intestines, wet weight of 1-m sections of the duodenum, jejunum, and ileum; length of the small intestine; and hot carcass weight (HCW). Sections of the small intestine and cecum were rinsed in $0.9 \%$ saline, inverted, and intact samples (approximately 2 $\times 2 \mathrm{~cm}^{2}$ ) were fixed in $10 \%$ neutral buffered formalin for histological analysis. Fixed tissues were paraffin embedded and sectioned $(5 \mu \mathrm{m})$ for hematoxylin and eosin staining and subsequent immunohistochemistry by Histoserv Inc. (Germantown, MD).

\section{Morphometry and BrdU Staining}

Mean villus height and crypt depth in the small intestine were determined by a single observer blinded to treatment from hematoxylin-and-eosin-stained sections using measures of 21 to 30 well-oriented villus-crypt units using an Olympus BX-40 microscope (Olympus
America Inc., Center Valley, PA) fitted with an Olympus DP-70 digital CCD camera. Captured images were analyzed and areas of interest quantified using ImagePro software (Media Cybernetics Inc., Rockville, MD). Mean villus height:crypt depth ratio was calculated for each animal as an index of mucosal atrophy (Slavin et al., 1980).

Formalin-fixed, paraffin-embedded sections were dewaxed in xylene and hydrated in a graded series of ethanol washes to deionized water. Microwave antigen retrieval was performed as described by Capuco et al. (2009); then, slides were washed $(3 \times 2 \mathrm{~min})$ with deionized water, and quenched in $3 \%$ hydrogen peroxide for $10 \mathrm{~min}$. Slides were washed once for $2 \mathrm{~min}$ with deionized water and then washing $(3 \times 2 \mathrm{~min})$ with Dulbecco's PBS (calcium and magnesium free). Tissue sections were blocked with $10 \%$ nonimmune goat serum (Histostain-Plus Broad Spectrum Kit; Invitrogen Corp., Carlsbad, CA) for 10 min before overnight incubation at $4^{\circ} \mathrm{C}$ in primary antibody (clone BMC-9318 catalog number 11170-376; 1:25 dilution in CAS block; Invitrogen Corp.). Slides then were washed with PBS and incubated for $30 \mathrm{~min}$ at room temperature in biotinylated secondary antibody, washed with PBS, and then incubated for $20 \mathrm{~min}$ in streptavidin-peroxidase conjugate. After washing with PBS, slides were incubated for 6 min in the dark in diaminobenzidine (DAB) according to the Liquid DAB Substrate Kit (Invitrogen Corp.), washed $(3 \times 2 \mathrm{~min})$ with deionized water, and then counterstained $1 \mathrm{~min}$ in hematoxylin (Invitrogen Corp.). Finally, slides were dehydrated in a series of ethanol washes, followed by xylene, and mounted with Permaslip (Alban Scientific Inc., St. Louis, MO).

Cell proliferation was quantified as the percentage of BrdU-labeled nuclear area to total nuclear area in 10 well-oriented crypts by capturing images as described above using an Olympus BX-40 microscope fitted with an Olympus DP-70 digital CCD camera. Captured images were analyzed and areas of interest quantified using Image-Pro software.

\section{Protein Tyrosine Nitration Analysis}

The presence of tyrosine-nitrated proteins as reflective of nitro-oxidative stress (Elsasser et al., 2012) in the ileum and cecum was detected by immunohistochemical localization of 3 '-nitrotyrosine antigens and further analyzed with regard to treatment effects by the application of quantitative image analysis measurement of antigen-specific pixel densities in cells. Nitrated proteins in tissues were visualized using rabbit antinitrotyrosine antiserum (1:5,000, kindly donated by J. Rodrigo, Cajal Institute for Neurobiology, Madrid, Spain) in conjunction with a traditional avidin-biotin 
complex goat anti-rabbit-conjugated horseradish peroxidase (Vectastain Elite; Vector Laboratories Inc., Burlingame, CA) deposition of $\mathrm{DAB}$ with nuclear counterstaining (Carrazzi's hematoxylin) as previously validated and described (Elsasser et al., 2004, 2007). Five photomicrographs of each tissue specimen per calf from the ileum and 1 specimen per calf from the cecum were collected across the length of the slide-mounted tissue using an Olympus BX-40 microscope equipped with a digital camera (Olympus DP-70 CCD) under the $10 \times$ objective. The cellular abundance of nitrotyrosine pixels was quantified using a validated image analysis rubric (Elsasser et al., 2004, 2007) as applied to the regions of the image constituting the villi and crypts, and lamina propria above the muscularis mucosae in the ileum, and the crypts and columnar epithelium of the mucosal layer of the cecum. Captured images were equalized in terms of contrast, brightness, and gamma using the software-driven internal best-fit equalization. The intensity of DAB color-specific staining was obtained by defining through color cube-based segmentation a spectrum-specific range of wavelengths, hues, and intensities that corresponded to those color attributes detectable by the same staining procedure applied to an internal control (liver specimen known to contain nitrotyrosine-positive and a gradient of associated pixels). To normalize the nitrotyrosine response as the average number of pixels per cell, nuclei were counted in the same captured frames by further subjecting the image to a standardized set of morphological filters to identify nuclear-specific objects and further separate defined, but closely-spaced, objects using a watershed split feature.

\section{Statistical Analyses}

Mean comparisons for carcass weight, gross intestinal measures, morphometry, and BrdU and nitrotyrosine immunostaining, were made using the GLM procedure of SAS (SAS Institute Inc., Cary, NC). The model included the fixed effects of infection status, treatment (buffer or GLP-2), block, and the interaction of infection and treatment. If interaction and fixed effects were significant $(P<0.05)$, further comparison of least squares means within treatment and infection were made using the PDIFF option of SAS. A $P$-value $\leq 0.05$ was considered significant and $\leq 0.1$ was considered a tendency for all statistical inferences. Data are presented as least squares means \pm standard error of the mean.

\section{RESULTS}

\section{Calf Responses and Gross Intestinal Measures}

Calves in the Eim-Buffer and Eim-GLP2 groups began shedding $E$. bovis oocysts by d 20 of infection. No calves in the noninfected groups shed oocysts at any time during the experiment. On average, noninfected calves had an abnormal stool for $1.2 \mathrm{~d}$ out of the final $11 \mathrm{~d}$ of the trial (Con-Buffer $=1.2 \mathrm{~d}$; Con-GLP2 $=$ $1.3 \mathrm{~d}$ ), whereas infected calves exhibited an abnormal stool an average of $8.2 \mathrm{~d}$ out of the final $11 \mathrm{~d}$ (EimBuffer $=8.0 \mathrm{~d}$; Eim-GLP2 $=8.3$ ), beginning as early as d 19 of infection. Average fecal scores on abnormal days were 0.9 in the noninfected calves (Con-Buffer $=$ 0.9 ; Con-GLP2 $=0.9$ ) and 2.0 in the infected calves $($ Eim-Buffer $=2.0$; Eim-GLP2 $=1.9)$. Several infected calves exhibited severe or bloody diarrhea during the experimental period and were bottle-fed Hydra-Lyte (Lloyd Inc., Shenandoah, IA) electrolyte replacement to treat dehydration. In addition, 1 calf in the Con-Buffer group exhibited diarrhea (fecal score 3) $7 \mathrm{~d}$ before slaughter and was administered Hydra-Lyte for $3 \mathrm{~d}$ and a single treatment with penicillin $\mathrm{G}$ as precautionary measures. The veterinary treatments were intended to prevent death of calves and were not expected to affect experimental measures. However, 1 calf in block 4 in the Eim-GLP2 group died on d 24 of the study due to complications associated with diarrhea. All measures for this calf were removed from statistical analyses.

Calves gained an average of $0.5,0.4,0.5$, and 0.5 $\mathrm{kg} / \mathrm{d}$ in the Con-Buffer, Con-GLP2, Eim-Buffer, and Eim-GLP2 groups, respectively. Table 1 summarizes the effects of GLP-2 treatment and E. bovis infection on intestinal measures of calves at slaughter.

No interaction $(P>0.17)$ of infection status by GLP-2 treatment was observed for any of the carcass measures evaluated. No effect of infection status was observed on wet weight of $1-\mathrm{m}$ sections of the duodenum $(P=0.46)$ or jejunum $(P=0.72)$, but $E$. bovis infection increased $(P=0.06)$ the weight of the ileum relative to noninfected calves. Treatment with GLP-2 had no effect on the weight of the duodenum $(P=0.16)$ or ileum $(P=0.36)$, but increased $(P=0.07)$ the mean weight of the jejunum relative to the buffer-treated groups. Within noninfected calves, GLP-2 treatment increased $(P=0.09)$ the section weight of the jejunum by $33 \%$ relative to buffer treatment. Large intestine weight as a percentage of $\mathrm{HCW}$ was increased by $E$. bovis infection $(P=0.01)$ and GLP-2 treatment $(P=0.03)$ relative to noninfected and buffer-treated groups, respectively. Within infected calves, GLP-2 treatment increased ( $P$ $=0.08)$ the mean large intestine weight by $14 \%$ relative to the Eim-Buffer group. Small intestine weight as a percentage of $\mathrm{HCW}$ also was increased $(P=0.01)$ by GLP-2 treatment relative to treatment with buffer. This effect was most evident in noninfected calves where mean small intestine weight was increased $(P=$ $0.03)$ by $25 \%$ in the Con-GLP2 versus the Con-Buffer group. In infected calves, the small intestine weight 


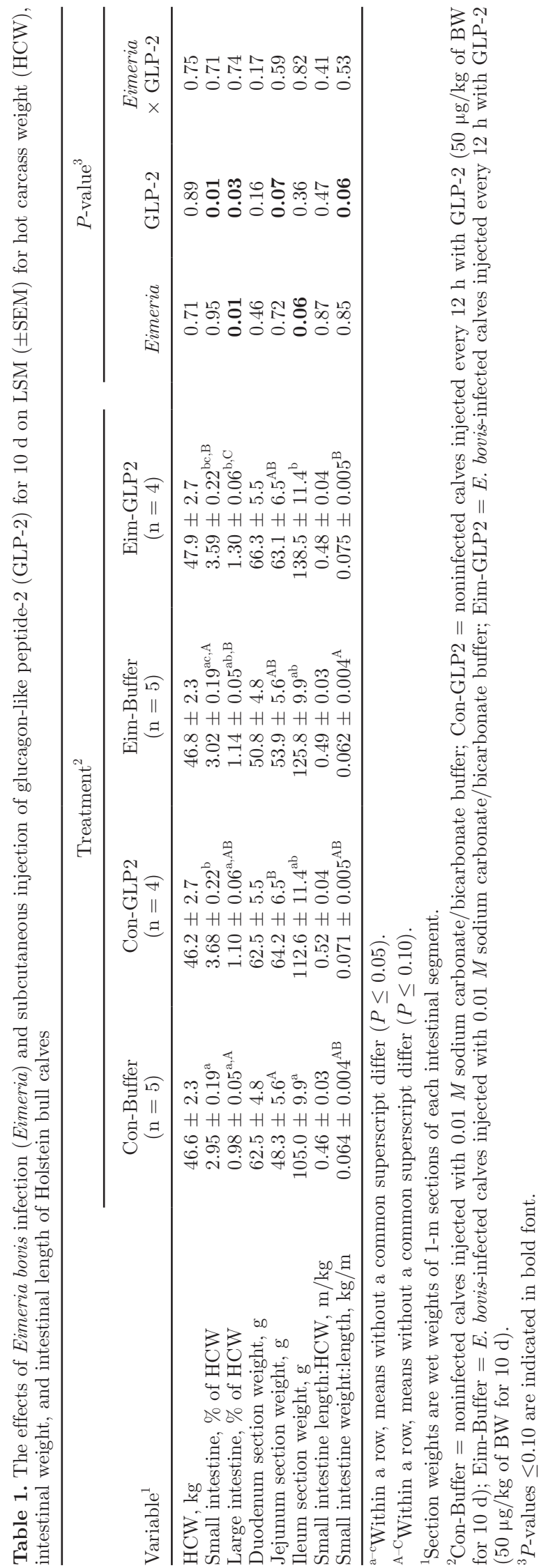

was increased $(P=0.08)$ by $19 \%$ in the Eim-GLP2 compared with the Eim-Buffer group. Length of the small intestine per unit of $\mathrm{HCW}$ was not affected by E. bovis infection $(P=0.87)$ or GLP-2 treatment $(P=$ $0.47)$, but the ratio of small intestinal weight to length was increased $(P=0.06)$ by GLP-2 treatment relative to buffer. This included an increase $(P=0.08)$ of $21 \%$ in the Eim-GLP2 compared with the Eim-Buffer group.

\section{BrdU Staining and Morphometry}

Table 2 summarizes the effects of E. bovis-infection status and GLP-2 treatment on BrdU labeling, villus height, and crypt depth in the small intestine. No interaction $(P \geq 0.42)$ was observed between the effect of infection status and GLP-2 treatment on BrdU labeling in the small intestine. No detectable interaction $(P \geq$ $0.16)$ or main effects $(P \geq 0.12)$ of $E$. bovis-infection status or GLP-2 treatment existed for villus height, crypt depth, or villus height:crypt depth ratio in small intestinal segments.

In the duodenum, labeling for BrdU in response to GLP-2 treatment relative to buffer treatment was not affected $(P=0.41)$, but in the jejunum was increased $(P=0.08)$, particularly within noninfected calves (LSM \pm SEM of $17.1 \pm 4.8 \%$ vs. $31.5 \pm 5.5 \%$ in Con-buffer and Con-GLP2, respectively; $P=0.08$ ). Representative images of the jejunum stained for BrdU in noninfected calves treated with buffer or GLP-2 are shown in Figures $1 \mathrm{~A}$ and $1 \mathrm{~B}$, respectively. In the ileum, labeling for BrdU was not affected $(P=0.98)$ by GLP-2 treatment relative to buffer treatment, but was decreased $(P=0.09)$ by $E$. bovis infection relative to a noninfected state.

\section{Protein Tyrosine Nitration Analysis}

The effects of $E$. bovis infection and GLP-2 treatment on abundance of tyrosine nitration in the ileum and cecum of calves are summarized in Figures 2A and 2B, respectively. Figures $2 \mathrm{C}$ and $2 \mathrm{D}$ show representative images of nitrotyrosine immunostaining in response to $E$. bovis infection and GLP-2 therapy in the ileum and cecum, respectively. No interaction $(P=0.22)$ existed between the effects of infection status and GLP-2 treatment on nitrotyrosine staining in the ileum, but an interaction $(P=0.005)$ was detected in the cecum. Infection with $E$. bovis caused an increase in the abundance of nitrotyrosine immunostaining in the ileum by approximately 3.8 fold $[E$. bovis-infected (LSM \pm SEM) $=6.0 \pm 0.8 \%$ by area vs. control $=1.6 \pm 0.8 \% ; P$ $=0.004$ relative to noninfected controls. Treatment with GLP-2 decreased nitrotyrosine immunostaining in the ileum (buffer $=4.9 \pm 0.8 \%$ vs. GLP-2 treatment $=2.7 \pm 0.9 \% ; P=0.09)$ relative to buffer-treated 
Table 2. The effects of Eimeria bovis infection (Eimeria) and subcutaneous injection of glucagon-like peptide-2 (GLP-2) for $10 \mathrm{~d}$ on LSM ( \pm SEM) for villus height, crypt depth, and cell proliferation as determined by 5-bromo-2'-deoxyuridine (BrdU) immunostaining in the ileum of Holstein bull calves

\begin{tabular}{|c|c|c|c|c|c|c|c|}
\hline \multirow[b]{2}{*}{ Variable } & \multicolumn{4}{|c|}{ Treatment $^{1}$} & \multicolumn{3}{|c|}{$P$-value ${ }^{2}$} \\
\hline & $\begin{array}{l}\text { Con-Buffer } \\
(\mathrm{n}=5)\end{array}$ & $\begin{array}{l}\text { Con-GLP-2 } \\
\quad(\mathrm{n}=4)\end{array}$ & $\begin{array}{c}\text { Eim-Buffer } \\
(\mathrm{n}=5)\end{array}$ & $\begin{array}{c}\text { Eim-GLP2 } \\
(\mathrm{n}=4)\end{array}$ & Eimeria & GLP-2 & $\begin{array}{l}\text { Eimeria } \\
\times \text { GLP-2 }\end{array}$ \\
\hline \multicolumn{8}{|l|}{ Duodenum } \\
\hline Villus height, $\mu \mathrm{m}$ & $403.7 \pm 54.1$ & $354.2 \pm 62.5$ & $284.1 \pm 54.1$ & $399.9 \pm 62.5$ & 0.54 & 0.58 & 0.19 \\
\hline Crypt depth, $\mu \mathrm{m}$ & $300.5 \pm 14.9$ & $303.7 \pm 17.2$ & $249.4 \pm 14.9$ & $301.4 \pm 17.2$ & 0.13 & 0.12 & 0.16 \\
\hline Villus height:crypt depth & $1.4 \pm 0.2$ & $1.2 \pm 0.2$ & $1.2 \pm 0.2$ & $1.3 \pm 0.2$ & 0.98 & 0.93 & 0.38 \\
\hline BrdU-positive nuclei, $\%$ of nuclear area & $18.6 \pm 4.0$ & $14.4 \pm 4.6$ & $16.5 \pm 4.0$ & $13.4 \pm 4.6$ & 0.73 & 0.41 & 0.89 \\
\hline \multicolumn{8}{|l|}{ Jejunum } \\
\hline Villus height, $\mu \mathrm{m}$ & $256.2 \pm 39.0$ & $248.4 \pm 45.1$ & $228.5 \pm 39.0$ & $308.1 \pm 45.1$ & 0.71 & 0.41 & 0.33 \\
\hline Crypt depth, $\mu \mathrm{m}$ & $321.8 \pm 26.1$ & $341.7 \pm 30.1$ & $295.4 \pm 26.1$ & $321.2 \pm 30.1$ & 0.42 & 0.43 & 0.92 \\
\hline Villus height:crypt depth & $0.8 \pm 0.1$ & $0.7 \pm 0.1$ & $0.8 \pm 0.1$ & $1.0 \pm 0.1$ & 0.35 & 0.60 & 0.17 \\
\hline BrdU-positive nuclei, $\%$ of nuclear area & $17.1 \pm 4.8^{\mathrm{A}}$ & $31.5 \pm 5.5^{\mathrm{B}}$ & $22.8 \pm 4.8^{\mathrm{AB}}$ & $28.3 \pm 5.5^{\mathrm{AB}}$ & 0.81 & 0.08 & 0.42 \\
\hline \multicolumn{8}{|l|}{ Ileum } \\
\hline Villus height, $\mu \mathrm{m}$ & $250.3 \pm 34.0$ & $269.8 \pm 39.3$ & $265.2 \pm 34.0$ & $289.3 \pm 39.3$ & 0.65 & 0.57 & 0.95 \\
\hline Crypt depth, $\mu \mathrm{m}$ & $312.2 \pm 21.6$ & $331.3 \pm 25.0$ & $323.7 \pm 21.6$ & $327.8 \pm 25.0$ & 0.87 & 0.63 & 0.76 \\
\hline Villus height:crypt depth & $0.8 \pm 0.1$ & $0.8 \pm 0.1$ & $0.8 \pm 0.1$ & $0.9 \pm 0.1$ & 0.56 & 0.58 & 0.92 \\
\hline BrdU-positive nuclei, $\%$ of nuclear area & $13.7 \pm 3.7$ & $15.4 \pm 4.2$ & $7.9 \pm 3.7$ & $6.4 \pm 4.2$ & 0.09 & 0.98 & 0.69 \\
\hline
\end{tabular}

A,B Within a row, means without a common superscript differ $(P<0.10)$.

${ }^{1}$ Con-Buffer $=$ noninfected calves injected with $0.01 \mathrm{M}$ sodium carbonate/bicarbonate buffer; Con-GLP2 = noninfected calves injected every $12 \mathrm{~h}$ with GLP-2 $(50 \mu \mathrm{g} / \mathrm{kg}$ of BW for $10 \mathrm{~d}$ ); Eim-Buffer = Eimeria-infected calves injected with $0.01 \mathrm{M}$ sodium carbonate/bicarbonate buffer; Eim-GLP2 = Eimeria-infected calves injected every 12 h with GLP-2 $(50 \mu \mathrm{g} / \mathrm{kg}$ of BW for $10 \mathrm{~d})$.

${ }^{2} P$-values $\leq 0.10$ are indicated in bold font. 

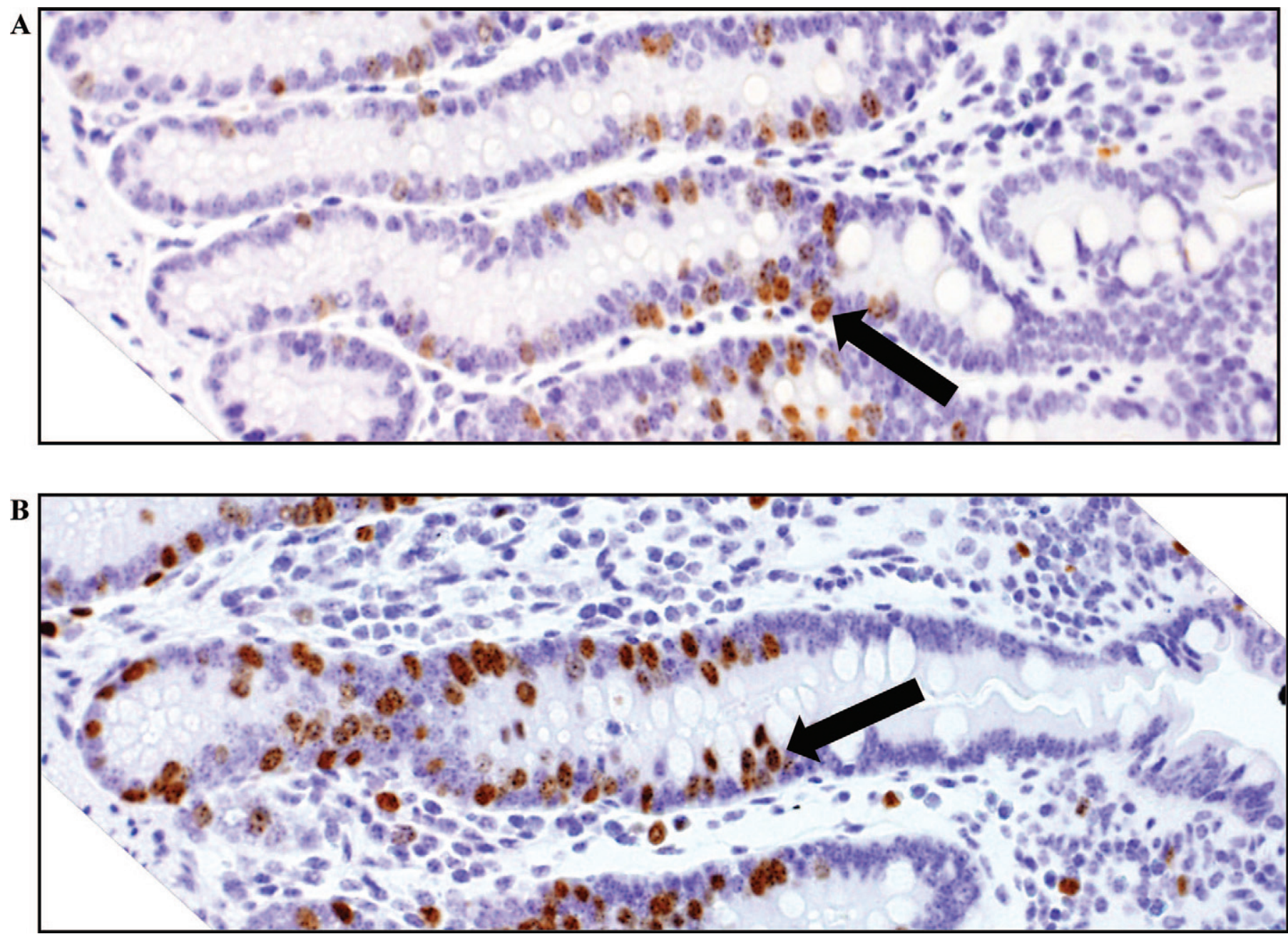

Figure 1. Representative light micrographs of crypts of the jejunum stained for 5-bromo-2'-deoxyuridine (BrdU). Images are from Holstein bull calves noninfected with Eimeria bovis and treated for $10 \mathrm{~d}$ with subcutaneous injections every $12 \mathrm{~h}$ with $0.01 \mathrm{M}$ sodium carbonate/bicarbonate buffer (A), or $50 \mu \mathrm{g}$ of glucagon-like peptide $2 / \mathrm{kg}$ of BW (B). Black arrows indicate crypt cells positively stained for BrdU (10× magnification).

controls. Within the ileum of E. bovis-infected calves, GLP-2 therapy reduced $(P<0.05)$ nitrotyrosine staining by 1.9 fold relative to buffer treatment (Eim-Buffer $=7.8 \pm 1.1 \%$ vs. Eim-GLP2 $=4.1 \pm 1.3 \%)$. In the cecum, nitrotyrosine staining was increased $(P \leq 0.001)$ in Eim-Buffer calves relative to all other groups. No difference $(P \geq 0.40)$ was observed in nitrotyrosine immunostaining among the Con-Buffer, Con-GLP2, and Eim-GLP2 groups. The GLP-2 therapy reduced $(P<$ 0.001 ) nitrotyrosine immunostaining in the cecum by $69 \%$ (3.2 fold) relative to buffer treatment in E. bovisinfected calves (Eim-Buffer $=824.3 \pm 75.2 .0$ pixels $/$ cell vs. Eim-GLP2 $=256.0 \pm 86.9$ pixels/cell).

\section{DISCUSSION}

Infection with the protozoan Eimeria is common in young calves (Lorenz et al., 2011), of which E. bovis occurs most typically and is one of the most pathogenic species (Friend and Stockdale, 1980). Oral inoculation with as few as 100,000 E. bovis causes diarrhea and lesions of the distal ileum, cecum, and colon, including edema, mucosal ulceration, and inflammation, which are most severe around d 19 of infection within the ileum and between d 18 to 26 in the cecum and colon (Friend and Stockdale, 1980). Due to these effects on the intestinal mucosa, experimental infection of newborn calves with 100,000 to 200,000 sporulated E. bovis oocysts was used as a model in the present study to assess the ability of GLP-2 to reduce damage to the intestinal mucosa in calves with diarrhea. Evaluation of GLP-2 effects on noninfected control calves also permitted the examination of baseline effects of GLP-2 treatment on intestinal parameters measured.

As anticipated, E. bovis-infected calves in the present study exhibited moderate to severe diarrhea beginning 
$\mathbf{A}$
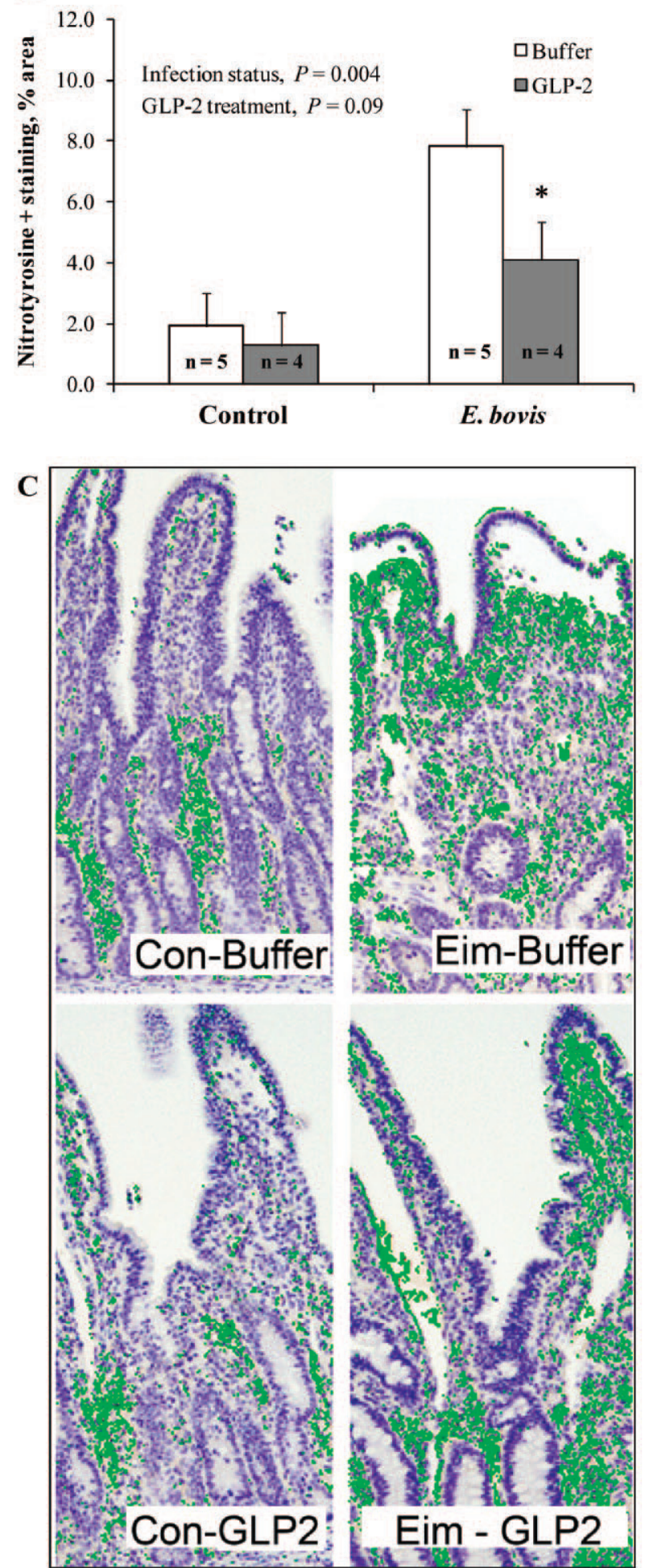
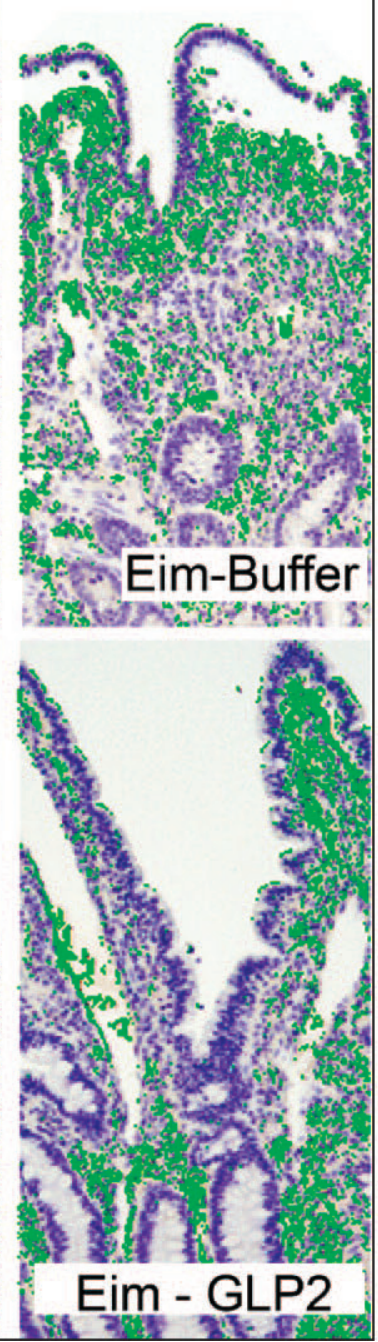

B

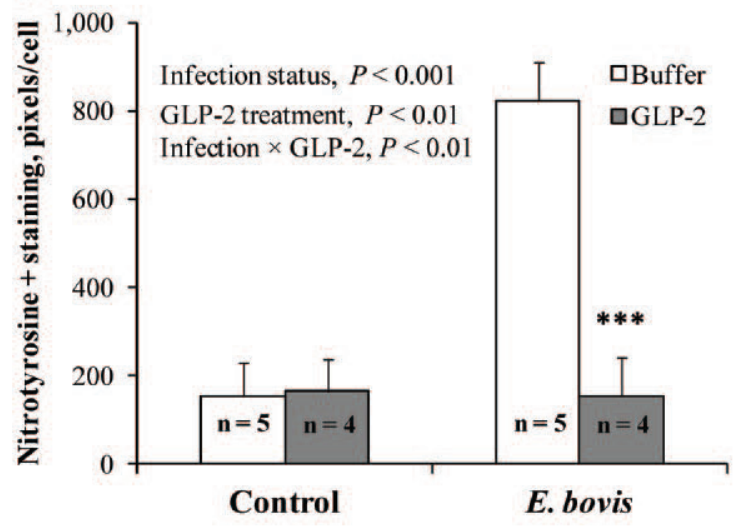

D

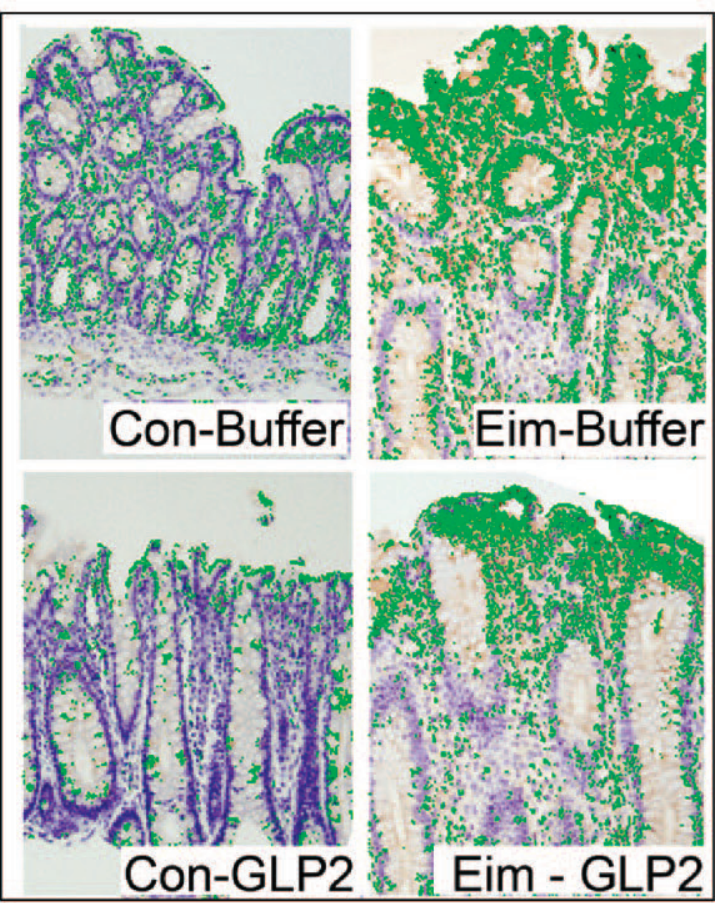

Figure 2. Effect of glucagon-like peptide 2 (GLP-2) treatment and Eimeria bovis infection on LSM ( \pm SEM) for protein tyrosine nitration immunostaining in the ileum (A) and cecum (B) of Holstein bull calves. Images represent nitrotyrosine immunostaining (green) in the ileum (C) and cecum (D) of calves by treatment group (10× magnification). Calves were noninfected (control) or infected with 100,000 to 200,000 sporulated E. bovis oocysts on d 0, and then injected subcutaneously on d 18 to 27 every $12 \mathrm{~h}$ with $0.01 \mathrm{M}$ carbonate/bicarbonate buffer or $50 \mu \mathrm{g}$ of GLP-2 $/ \mathrm{kg}$ of BW. Calves were slaughtered on d 28. Con-Buffer = noninfected, buffer treated; Eim-Buffer $=E$. bovis infected, buffer treated; Con-GLP2 = noninfected, GLP-2 treated; Eim-GLP2 = E. bovis infected, GLP-2 treated. *Difference within E. bovis-infected groups $(P<0.05) ;{ }^{* * *}$ difference within $E$. bovis-infected groups $(P<0.001)$. 
as early as d 19 of infection, and had an average fecal score of 2.0, with many calves having hemorrhagic diarrhea at some point during the period of oocyst shedding. The protozoan's lifecycle is localized to the ileum, cecum, and large intestine. The level of Eimeria infection in the present study significantly increased the weight of the large intestine as a percentage of $\mathrm{HCW}$, increased the weight of the ileum, and tended to reduce crypt cell proliferation in the ileum. However, infection was not severe enough to negatively affect ADG or HCW relative to noninfected controls. The intestinal weight responses observed were likely due to the presence of edema and immune cell infiltration, particularly in the cecum and colon (Friend and Stockdale, 1980), associated with E. bovis infection. Damage to the ileal mucosa and crypts from infection results from rampant sexual reproduction (gamogonic phase) and shedding of gamonts and oocysts, which peaks around d 19 to 22 (Friend and Stockdale, 1980; Daugschies and Najdrowski, 2005; Sühwold et al., 2010) and likely accounts for the decrease in cell proliferation in the crypts measured at slaughter (d 28), as evaluated by BrdU labeling. However, no significant differences were detected in villus height or crypt depth in the ileum in response to $E$. bovis infection as one might expect from the replicating gamonts and release of oocysts. Failure to detect a difference could be due to the timing of tissue sampling relative to the stage of the protozoan lifecycle within the host, or the specific location within the ileal tissue collected.

A 10-d treatment with GLP-2 increased weights of both the small and large intestines as percentages of $\mathrm{HCW}$, and tended to increase the 1-m section weight of the jejunum and corresponding cell proliferation within the jejunum, particularly within the noninfected calves. In addition, small intestinal density as assessed by the ratio of small intestine weight to length was increased by GLP-2 treatment, which was most evident in infected calves. These results are consistent with those observed in mice (Drucker et al., 1996), rats (Sigalet et al., 2006), and cattle (Taylor-Edwards et al., 2011). For example, GLP-2 treatment for as little as 6 to 10 $\mathrm{d}$ increased small intestine weight and mucosal thickness in mice (Drucker et al., 1996). Sigalet et al. (2006) found that GLP-2 treatment of rats following resection of the ileum and portions of the jejunum (removal of $80 \%$ of the distal small intestine) increased total weight of the remaining small bowel and small bowel weight as a percentage of $\mathrm{BW}$, and increased total protein and DNA content of the jejunum. Likewise, Taylor-Edwards et al. (2011) demonstrated that treatment of 3.5-mo-old Holstein calves with the same dosage of GLP-2 used in the current experiment for the same duration increased the weight of the small intestine as a percentage of
$\mathrm{HCW}$, the ratio of mass to length of the small intestine, and $0.5-\mathrm{m}$ section weight of the jejunum. In addition, they found that GLP-2 treatment increased crypt cell proliferation in all segments of the small intestine. However, none of these studies found measurable effects of GLP-2 on the large intestine (if examined) as seen in the present experiment. An early study in mice did find that subcutaneous GLP-2 injections for $10 \mathrm{~d}$ increased the DNA content, protein content, and weight of the colon (Litvak et al., 1998). Failure to detect measurable differences in villus height, crypt depth, or villus height:crypt depth ratio in the ileum of our calves in response to GLP-2 treatment was likely due to the high level of variation observed in these variables among calves. Variation in the present study was similar to that reported by Kehoe et al. (2008) in calves of similar age. Therefore, a much larger sample size appears to be needed to detect treatment differences in morphological measures under these experimental conditions or in calves of this age group.

Perhaps of greatest interest relative to the potential beneficial effects of GLP-2 therapy on the gut, recent research indicates that GLP-2 has antioxidant activity in intestinal cells and affects glutathione peroxidase, catalase, and superoxide dismutase activities (ArdaPirincci and Bolkent, 2011). Therefore, GLP-2 could also influence formation of peroxynitrite from the reaction of superoxide and nitric oxide during inflammation, and the creation of protein tyrosine nitration in the intestinal mucosa. Eimeria bovis is known to cause macrophage infiltration of the ileum, cecum, and colon of infected calves, triggering production of oxygen radicals, nitric oxide, and cytokine release (Taubert et al., 2009). Such reactions may also increase nitrotyrosine formation in these tissues, leading to altered protein function ranging from inhibition to activation, ultimately affecting cellular functions such as growth, metabolism, apoptosis, and necrosis (Elsasser et al., 2012). Thus, the present study provided an opportunity to examine the abundance of nitrotyrosine in the ileum and cecum during E. bovis infection, as well as the ability of GLP-2 to ameliorate any observed effects.

In the present study, it was clearly shown that immunostaining for nitrotyrosine in the ileum and cecum of calves at slaughter (d 28 of infection) was significantly increased by over 3 fold among E. bovis-infected calves. This observation is consistent with a proinflammatory response that we would expect in these tissues, where lesions from $E$. bovis are most prevalent. A previous study of cattle has shown increased tissue nitrotyrosine abundance in response to parasitic infection, including muscle tissue infected with the protozoan Sarcocystis cruzi (Elsasser et al., 2012). Remarkably, treatment with GLP-2 tended to reduce nitrotyrosine staining in 
the ileum across all calves, but was most evident in E. bovis-infected calves where abundance of nitrotyrosine was reduced by almost 2 fold by GLP-2 treatment relative to buffer-treated infected calves. In the cecum, this effect was even more pronounced, where GLP-2 therapy reduced nitrotyrosine immunostaining by $69 \%$ relative to buffer treatment during E. bovis infection. In fact, the presence of nitrotyrosine staining in EimGLP2 calves was reduced to levels equivalent to noninfected calves, indicating the beneficial effects of GLP-2 on nitro-oxidative state of ileocecal mucosa during inflammation. By reducing the prevalence of protein tyrosine nitration in the gut, GLP-2 therapy promotes tissue recovery and reduces the negative effects of the proinflammatory response on cell growth, metabolism, and function.

\section{CONCLUSIONS}

The present study demonstrated that GLP-2 treatment increases epithelial growth in the jejunum and intestinal weight of neonatal calves. Most importantly, GLP-2 therapy reduced the detrimental effects of protein tyrosine nitration in the gut of calves with coccidiosis. Implications are that GLP-2 therapy provides promise in ameliorating potentially life-long negative effects of nitro-oxidative stress in the gut associated with diarrhea in the growing animal. This work provides the foundation for future development of practical strategies to administer GLP-2 therapy in a commercial livestock production setting.

\section{ACKNOWLEDGMENTS}

The authors acknowledge the excellent technical support of Mary Bowman, Marsha Campbell, Donald Carbaugh, Mary Niland, Dennis Hucht, Meghan Heffron, James Piatt, and Research Support Services staff at the USDA-ARS (Beltsville, MD) who contributed to this project. Mention of trade names or commercial products in this article is solely for the purpose of providing specific information and does not imply recommendation or endorsement by the US Department of Agriculture. The USDA is an equal opportunity provider and employer.

\section{REFERENCES}

Arda-Pirincci, P., and S. Bolkent. 2011. The role of glucagon-like peptide-2 on apoptosis, cell proliferation, and oxidant-antioxidant system at a mouse model of intestinal injury induced by tumor necrosis factor-alpha/actinomycin D. Mol. Cell. Biochem. 350:13-27.

Burrin, D., X. Guan, B. Stoll, Y. M. Petersen, and P. T. Sangild 2003a. Glucagon-like peptide 2: A key link between nutrition and intestinal adaptation in neonates? J. Nutr. 133:3712-3716.

Burrin, D. G., B. Stoll, and X. Guan. 2003b. Glucagon-like peptide 2 function in domestic animals. Domest. Anim. Endocrinol. 24:103-122.
Capuco, A. V., C. M. Evock-Clover, A. Minuti, and D. L. Wood. 2009 In vivo expansion of the mammary stem/progenitor cell population by xanthosine infusion. Exp. Biol. Med. (Maywood) 234:475-482.

Connor, E. E., R. L. Baldwin 6th, A. V. Capuco, C. M. Evock-Clover, S. E. Ellis, and K. S. Sciabica. 2010. Characterization of glucagonlike peptide 2 pathway member expression in bovine gastrointestinal tract. J. Dairy Sci. 93:5167-5178.

Daugschies, A., and M. Najdrowski. 2005. Eimeriosis in cattle: Current understanding. J. Vet. Med. B. Infect. Dis. Vet. Public Health $52: 417-427$

Drucker, D. J. 2005. Biologic actions and therapeutic potential of the proglucagon-derived peptides. Nat. Clin. Pract. Endocrinol. Metab. 1:22-31.

Drucker, D. J., P. Ehrlich, S. L. Asa, and P. L. Brubaker. 1996. Induction of intestinal epithelial proliferation by glucagon-like peptide 2 . Proc. Natl. Acad. Sci. USA 93:7911-7916.

Elsasser, T. H., S. Kahl, A. V. Capuco, and W. Schmidt. 2012. Effects of stress on endocrine and metabolic processes and redirection: Cross talk between subcellular compartments. Domest. Anim. Endocrinol. 43:132-145.

Elsasser, T. H., S. Kahl, C.-J. Li, J. L. Sartin, W. M. Garrett, and J. Rodrigo. 2007. Caveolae nitration of JAK-2 at the ${ }_{1007} \mathrm{Y}_{-1008} \mathrm{Y}$ site: Coordinating inflammatory response and metabolic hormone readjustment within the somatotropic axis. Endocrinology 148:3803-3813.

Elsasser, T. H., S. Kahl, C. MacLeod, B. Nicholson, J. L. Sartin, and C. Li. 2004. Mechanisms underlying growth hormone effects in augmenting nitric oxide production and protein tyrosine nitration during endotoxin challenge. Endocrinology 145:3413-3423.

Friend, S. C. E., and P. H. G. Stockdale. 1980. Experimental Eimeria bovis infection in calves: A histopathological study. Can. J. Comp. Med. 44:129-140.

Heinrichs, A. J., and B. S. Heinrichs. 2011. A prospective study of calf factors affecting first-lactation and lifetime milk production and age of cows when removed from the herd. J. Dairy Sci. 94:336341.

Kehoe, S. I., A. J. Heinrichs, C. R. Baumrucker, and D. L. Greger. 2008. Effects of nucleotide supplementation in milk replacer on small intestinal absorptive capacity in dairy calves. J. Dairy Sci. 91:2759-2770.

Litvak, D. A., M. R. Hellmich, B. M. Evers, N. A. Banker, and C. M. Townsend Jr.. 1998. Glucagon-like peptide 2 is a potent growth factor for small intestine and colon. J. Gastrointest. Surg. 2:146150 .

Lorenz, I., J. Fagan, and S. J. More. 2011. Calf health from birth to weaning. II. Management of diarrhea in pre-weaned calves. Ir. Vet. J. 64:9.

Lovshin, J., and D. J. Drucker. 2000. New frontiers in the biology of GLP-2. Regul. Pept. 90:27-32.

McLeod, K. R., R. L. Baldwin VI, M. B. Solomon, and R. G. Baumann. 2007. Influence of ruminal and postruminal carbohydrate infusion on visceral organ mass and adipose tissue accretion in growing beef steers. J. Anim. Sci. 85:2256-2270.

Sigalet, D. L., O. Bawazir, G. R. Martin, L. E. Wallace, G. Zaharko, A. Miller, and A. Zubaidi. 2006. Glucagon-like peptide-2 induces a specific pattern of adaptation in remnant jejunum. Dig. Dis. Sci 51:1557-1566.

Slavin, G., C. Sowter, K. Robertson, S. McDermott, and K. Paton. 1980. Measurement in jejunal biopsies by computer-aided microscopy. J. Clin. Pathol. 33:254-261.

Sühwold, A., C. Hermosilla, T. Seeger, H. Zahner, and A. Taubert. 2010. T cell reactions of Eimeria bovis primary- and challengeinfected calves. Parasitol. Res. 106:595-605.

Taubert, A., J. H. Behrendt, A. Sühwold, H. Zahner, and C. Hermosilla. 2009. Monocyte- and macrophage-mediated immune reactions against Eimeria bovis. Vet. Parasitol. 164:141-153.

Taylor-Edwards, C. C., D. G. Burrin, J. J. Holst, K. R. McLeod, and D. L. Harmon. 2011. Glucagon-like peptide-2 (GLP-2) increases small intestinal blood flow and mucosal growth in ruminating calves. J. Dairy Sci. 94:888-898. 